\title{
Nucleoside Analog DFP-10917
}

National Cancer Institute

\section{Source}

National Cancer Institute. Nucleoside Analog DFP-10917. NCI Thesaurus. Code C116744.

A deoxycytosine analog with potential antineoplastic activity. Upon administration, DFP10917 is phosphorylated to generate its nucleotide form that functions as a deoxycytosine mimic and is incorporated into DNA in tumor cells. This causes DNA strand breaks during polymerization due to beta-elimination during the fidelity checkpoint, which results in G2/M phase-arrest and tumor cell apoptosis. 